\title{
Impact of Organisational Commitment on Employee Productivity During Covıd-19: Evidence from Afghanistan And India
}

\author{
Mohammad Qais Rezvania, Nirmala Chaudhary', Ragif Huseynov', Maohua Lid, \\ Anjali Sharma ${ }^{e}$, Raiba Jafarova ${ }^{f}$, Chimnaz Huseynova ${ }^{g}$ \\ a University School of Management, Kurukshetra University, Kurukshetra, India rezvaniqais@gmail.com \\ Contact no. +91-8570058083 \\ b Kurukshetra University, Kurukshetra, India profnirmala66@gmail.com \\ c Faculty of Economics and Management, Azerbaijan Technological University, Ganja, Azerbaijan \\ ragif1984@gmail.com \\ d Institute for Corporate Social Responsibility, Xi’an Siyuan University, Xi’an, China maohua.li@qq.com \\ e University School of Management,Kurukshetra University, Kurukshetra, India anjali.usm@kuk.ac.in \\ ${ }^{\mathrm{f}}$ Faculty of Agricultural Economics, Azerbaijan State Agriculture University, Ganja, Azerbaijan \\ raibacafarova@mail.ru \\ sFaculty of Economics and Management, Azerbaijan Technological University, Ganja, Azerbaijan \\ cimnazhuseynova2020@gmail.com
}

\begin{tabular}{|c|c|}
\hline A B S T R A C T & ARTICLE INFO \\
\hline $\begin{array}{l}\text { The paper examines the impact of COVID-19 on } \\
\text { competitiveness and how organizational commitment and } \\
\text { productivity have changed as a result of changes in processes, } \\
\text { practices, or regulations. This paper analyses how employees } \\
\text { fared during COVID in two countries, namely Afghanistan and } \\
\text { India and the impact on organizational commitment and } \\
\text { productivity. The research paper is based on secondary data } \\
\text { and conceptual analysis of COVID-19 conditions or how this } \\
\text { covetous environment affects their competitors, work } \\
\text { environment, or fight for their rights. Moreover, the authors } \\
\text { delved into how human capital management lead to } \\
\text { organizational efficiency. Factors like (1) workplace safety, (2) } \\
\text { targeted recruitment, (3) self-managed decision-making teams } \\
\text { and decentralization, and (4) pay policy were all investigated. } \\
\text { Employee engagement is widely assumed to influence } \\
\text { organizational commitment, employee productivity, employee } \\
\text { dedication, and, most importantly, it will generate comparative } \\
\text { advantages for organizations. The primary goal of this research } \\
\text { was to discover how people work efficiently and effectively } \\
\text { with commitment and dedication during COVID-19. }\end{array}$ & $\begin{array}{l}\text { Keywords: Employee productivity, } \\
\text { organizational commitment, Covid-19, } \\
\text { Afghanistan, India. } \\
\text { *Corresponding author: } \\
\text { rezvaniqais@gmail.com } \\
\text { (Mohammad Qais Rezvani) } \\
\text { Article history: } \\
\text { Received: } 15.10 .2021 \\
\text { Revised: } 21.11 .2021 \\
\text { Accepted: 02.12.2021 } \\
\text { DOI: https://doi.org/10.51410/jcgirm.8.2.5 }\end{array}$ \\
\hline
\end{tabular}




\section{INTRODUCTION}

\subsection{A BRIEF EXPLANATION}

COVID-19 is a worldwide tragedy where people experience unexpected disruptions in their society, family, and workplace, resulting in mental stress.

COVID-19 primarily affects workers' personal and professional lives, causing anxiety, frustration, and burnout. Unattended emotions can harm workers' morale and commitment, resulting in poor work quality, errors, and, ultimately, the organization's survival in difficult times.

Employee commitment to the organization is critical in an organization, and it has a direct impact on productivity. During the difficult times of the Covid pandemic, it was difficult for HR managers to keep their employees committed to the work to maintain the optimum level of productivity. Employees may become less committed to their work during this period due to salary reductions, work from home, mental stress, fewer engagement activities offered by the organization, a lack of a good working environment (office space), or a lack of resources (internet and other devices).

According to Brian Kropp, Gartner HR Chairman of Resources Practice, most companies focused on scenario preparedness and the organizational reactions required for business continuity. He states, "However, such plans frequently fail to address employees' ability to focus or influence their work."

HR should enable managers to implement six specific practices to ensure workers receive the necessary support to overcome the emotional response.

During the first phase of the COVID 19 crisis, most businesses worked hard to ensure their employees' basic needs' protection, stability, and security. These requirements, however, change and necessitate a more advanced approach as organizations progress to the next stage. Our research has yielded three overviews, each with actionable steps to assist employees in the next phase of the crisis.

Personnel managers have made significant changes in recent months to meet the most pressing needs of their workforce, and what is important in this situation is to be present, empathize, and be completely transparent.

In addition to basic needs like security and safety, employee well-being and productivity are heavily influenced by three other factors: trusting relations, social cohesion, and individual goals. Therefore, managers should facilitate the development of these areas through priority actions that meet a wide range of criteria for most people. 
Changes among people are frequent (and sometimes unexpected). Some people fail, while others succeed. Employees are segmented so that customers adapt and are relevant to their specific needs, using a combination of science, technology, data, and analysis.

Employee motivation and actions must be met according to needs-based motivation theories. In the case of employee experience management, organizations must meet essential influential needs of the larger workforce while taking stock of the specific requirements of various segments. Our findings show a strong correlation between employees' reported needs and the factors that influence their loyalty, well-being, and work performance. The table below shows the highest personnel expectations and performance drivers, organized by key themes of staffing experience.

\subsection{DATA}

Between 3 January 2020 to 23 July 2021, 143,439 confirmed cases of COVID-19 were reported to the WHO in Afghanistan, with 6,357 deaths. On 18 July 2021, a total of 1,094,257 vaccine doses were administered. Afghanistan has a population of 31,6 million people, with rural areas accounting for 71.5 per cent of the population.

India has a population of 1.3 billion people. The country faces numerous challenges in its fight against COVID-19. The World Health Organization has stated that "the pandemic's fury depends on how Indians handle it." According to WHO reports in India, 31.257.720 confirmed cases of COVID19 were reported between 3 January 2020 to 22 July 2021, 418.987 deaths were reported, and a total dose of 377.352.501 vaccine doses was administered at the beginning of 5 July 2021.

COVID-19 has impacted all organizations by causing mental, social and financial harm to their employees. As the company's most valuable asset, employees should be given undivided attention, and each organization should strive to meet its employees' basic needs. In order to keep employees working with commitment and efficiency, organizations must change their policies according to the needs of the time.

Most information and technology-based organizations have adopted a work-from-home policy for their employees. However, accepting this policy presents a significant challenge to the HR manager to keep employees engaged and committed to their work.

\section{ORGANIZATIONAL COMMITMENT AND EMPLOYEE PRODUCTIVITY}

PAGE 61| Journal of Corporate Governance, Insurance, and Risk Management | 2021, VOL. 8, Series. 2 
Much research has been conducted on organizational commitment, but still, there are several issues that an organization faces due to a less committed workforce. According to Forbes, organizations face a dissatisfied and less committed workforce because of: poor supervisory support, lack of meaningfulness and purpose, unfair treatment, poor acknowledgement/recognition practices, job safety and security, and unequal rewards.

Organizational commitment is defined by Steers et al. (2001) as an employee's involvement in an organization based on his or her strong belief in the organization and its goals and values; it is the wishful behaviour and the strong desire to continue working for the organization. Meyer and Allen (1997) have defined commitment in the form of three different psychological states, which influence the desire of an employee to continue working in the organization. First, emotional involvement and belongingness are termed affective commitment. The behaviour of an employee related to the intention of leaving an organization is termed as continuance commitment; it is the feeling of an employee that they will lose more if they leave the organization than they will gain, it can be in the form of prestige, income, friendship or social loss. Finally, normative commitment is related to the obligation to remain in the organization ethically because it has provided the training and spent money on their development. Jaros et al. (1993) define affective commitment as the level of attachment of an employee in terms of loyalty, affection, belongingness and pleasure. Continuance commitment is explained as staying in the organization because he/she cannot afford the cost of leaving the organization. The third component is a moral commitment, which means that an employee stays because of the goals, values, and mission.

From the above definitions of the components of organizational commitment, it is clear that a committed employee is an asset to the organization. Therefore, every organization should keep its employee committed to the organization and their work to achieve the organization's optimum level of productivity and goals.

Organizational commitment and productivity are directly related, and it is universally accepted that a high level of commitment in employees contributes to achieving organizational goals. Committed employees work for primary organizational goals with efficiency and profitability. The following literature was reviewed to get an idea of research being conducted in this domain.

\section{Literature Review}

Many of the world's poorest and most vulnerable people live and work in the informal sector, and more than half of the population of industrialized countries lives and works in the informal economy. According to an ILO report, COVID-19 in India is likely to result in the expansion of over 400 million informal workers, as well as a significant decline in demand and a lack of income in sectors such as hospitality and accommodation, retail and wholesale, business services, construction, and 
manufacturing facilities. Moreover, the average business in Afghanistan's central economic hub has indicated that the ongoing COVID-19 pandemic may only allow them to remain open for another two months. These findings were revealed in a COVID-19 Business Pulse Survey by the IFC and World Bank in collaboration with USAID. The survey included over 380 companies employing five or more people in the agricultural, manufacturing, and service sectors. It assisted policymakers in tracking the pandemic's effects. The information is based on 146 secondary sources. The findings highlight the most pressing issues and challenges confronting India and Afghanistan, primarily farm labourers, household workers, healthcare workers, daily wage workers, and so on (Mohammad Qais Rezvani et al., 2020).

The COVID-19 outbreak impacted nearly every sector, particularly Afghanistan's education system, including universities worldwide. To that end, the researcher investigated the impact of COVID-19 on the academic success and satisfaction of Afghan students with Online Teaching. It also investigated the significant differences in academic achievement and satisfaction among students enrolled in gender-specific online learning. There were 1231 participants from both public and private universities in Afghanistan, including 867 men and 364 women. Statistical analyses, both inferential and descriptive, have been performed. According to the findings of this study, COVID-19 harmed Afghan students' academic achievements, and students were extremely dissatisfied with online instruction during this critical period. In addition, the study found significant differences in academic performance and satisfaction with online teaching based on gender. Several implications and recommendations were made in light of the study's findings (Hashemi, 2021).

The purpose of this paper is to examine the practical behaviour of hotels in managing personnel during COVID-19 and to assess the impact of COVID-19 on the well-being of hotel employees using qualitative thematic analysis. This study demonstrates HRM practices that organizations can use to effectively manage their employees during times of uncertainty. HRM practices aimed at employees have a significant impact on their well-being. This paper incorporates insights from a good human resource management framework based on a job-demand model. The paper emphasizes themes that confirm and expand on existing wellness theories and models. The findings are significant for politicians because they provide guidance in times of difficulty for effective human management (Agarwal, 2021).

Many organizations are changing as the coronavirus (COVID-19) spreads rapidly worldwide. Many businesses have converted their entire workforce to temporary and remote communications. As a result, employee participation is expected to change. This study investigates and statistically evaluates factors that may influence employee participation levels. Data was collected from 208 people through an online questionnaire in India. US-14 was used to compute the engagement values (Utrecht Work Engagement Scale). The authors used multiple regression analysis to look at the impact of ten 
different variables. Regression results show that the correct virtual instruments, contact between leaders, mental medical checks, and virtual training increase employee engagement. Female employees work from home at a higher rate than male employees. The number of children has a negative impact on employee engagement. When there are more children, employees' virtual involvement decreases. Finally, virtual teamwork, marital status, and entertainment tools have no significant impact on employee engagement. Based on the research findings, this study makes a few recommendations. First, businesses should make it possible to improve virtual tools such as internet speed and computer configuration. Second, wage workers should not have their hours reduced. Third, top management in organizations should communicate with employees regularly, increase virtual training, and encourage employees to undergo regular psychiatric examinations (Chaudhary et al., 2021).

This paper provides a comprehensive diagnosis of job satisfaction indexes in the Indian IT Sector during the COVID-19 period and factors that can be used to improve them. It focuses on the relative importance of employee satisfaction factors and their impact on employee satisfaction. The study also looks at the differences between factors that contribute to internal and external job satisfaction. It investigates the impact of age, gender, and management/non-management differences on work satisfaction attitudes. A quantitative (survey) method was used in the study, with a questionnaire sent to 355 IT staff (front and leaders) across India. There were 207 correct answers. The data was then analyzed using the Statistical Package for the Social Sciences (SPSS) version 22.5, using descriptive statistics, the Mann Whitney test, and the Kruskal Wallis test. According to the findings, IT employees were somewhat satisfied with their work. The results show that the most critical factors contributing to work satisfaction during COVID-19 are working conditions, the opportunity to experiment with one's method, and the coordination of coworkers. In addition, job stability has been a source of concern and dissatisfaction. External satisfaction factors have also been significantly positive in the analysis. As a result, the findings urge IT company management to promote intrinsic satisfaction factors to increase overall employee satisfaction, increasing company productivity (Arora \& Vyas, 2020).

A paper reviewed by senior hotel managers in Spain examines the number of interconnections between these variables. It demonstrates that organizational resilience and CSR practice increase managers' perceived job security and organizational involvement. COVID-19's organizational response influences workers' perception of protection and strength. As a result, hotels should increase operational flexibility and invest in CSR to assist management teams in the event of future catastrophic incidents (Filimonau et al., 2020).

Job and family positions have changed dramatically due to the worldwide COVID-19 pandemic. However, businesses can do little to improve working conditions and certain social concerns. By 
introducing an individual-focused approach, Vaziri et al. (2020) investigate improvements in workfamily interfaces before and after COVID-19 (Vaziri, H. et al., 2020).

This study also discovered a positive and significant impact on work-family relationships and employee performance on adaptability readiness. This new study proposed a model for increasing employee efficiency among Tangerang part-time packaging workers by improving work-life conflict management strategies and the ability to adapt. This research could aid worker preparation for the Fourth Industrial Revolution (Radita et al., 2021).

A COVID-19 crisis has had a long-term impact on nearly every aspect of human life worldwide. Moreover, the crisis has had an adverse effect. Therefore, the purpose of this study was to look into the impact of COVID-19 on employee insecurity, health complaints during isolation, risk-taking behaviour, and organizational change on job-related attitudes (work morale and job satisfaction), as well as staff turnover intentions in the hospitality industry (Demirovi et al., 2021).

This study aims to provide a critical understanding and synthesis of philosophical and empirical research into and the practice of corporate social responsibility (CSR), particularly in the aftermath of the COVID-19 pandemic. This research will show how it is valuable and significant. The authors explain why CSR can have positive and negative outcomes and potential feedback and policy recommendations (Ogden et al., 2020).

This article looks at five research areas that COVID's impact on employment: work loss, job shifts, job outcomes, management, and help. It also looks at COVID's impact on home life - home life changes, children's changes, child care (Venkatesh, 2020). Furthermore, to help the community during this pandemic, the article will discuss general research guidelines and concerns for researchers, editors, and reviewers (Venkatesh, 2020).

The COVID-19 time frame has positively impacted some aspects of an employee's life while harming others. The study concentrates on the relationships and dedication of employees who were influenced by COVID-19. An employee's success depends on happiness, and a happy employee paves the way for his or her company's success. A secure environment is an essential factor in this. Positive employee-employer relationships are essential for increasing employee and business morale and efficiency. On the other hand, employee dedication is related to efficiency and success in various ways. Employee presence demonstrates an employee's passion and dedication to a specific job (Kaushik, 2020).

\section{Objectives of the study}

- To Evaluate the effect of COVID-19 on employees' efficiency and organizational responsibilities. 
- To evaluate the impact of COVID-19 on the Organisational Commitment of employees.

- To learn about the conditions faced during Covid-19 in Afghanistan and India.

\section{Statement of the problem}

During the difficult times of COVID-19, HR managers have found it challenging to keep their employees committed to their work to contribute to maximum productivity with efficacy and effectiveness. A dedicated employee is a valuable asset to the organization, and appropriate steps should be taken to engage and satisfy the employee. People in this field are more concerned with the impact of job satisfaction on organizational engagement, but in human resources, employee efficiency and organizational commitment are still unexplored territories.

\section{Interpretation and analysis}

Based on extensive literature reviews, existing studies have discovered the following techniques for increasing organizational productivity and commitment. HR should enable managers to implement six specific practices to ensure that workers receive the necessary support to overcome the emotional response.

\subsection{The need for help for employees}

Management must identify signs of distress in their employees through discussions and direct observation. To facilitate frequent conversations between managers and employees, HR should advise management on how to answer important questions arising from the COVID-19 pandemic, such as alternative working models, safety and employment prospects, the effect on employees, and workplace conflicts. This guidance may include discussion guides, instructions, or e-mail reminders of the most recent changes and general guidelines.

\subsection{Encourage dialogue to create understanding}

Managers must collaborate with employees in two-way interactions to ensure that communication actions benefit rather than harm them. Employees benefit from two-way communication between managers and staff because they have the information and points of view they need to interact and process negative feelings and improve their sense of strength. HR leaders must allow managers to participate in bilateral dialogues about the positive and negative effects of the recent COVID-19 outbreak.

\subsection{Using clearness goals}

In a competitive business climate, a direct correlation between individual success and the achievement of business goals will increase workers' trust in the importance of their work. Staff will remain PAGE 66| Journal of Corporate Governance, Insurance, and Risk Management | 2021, VOL. 8, Series. 2 
focused, optimistic, and objective if expectations are communicated and regularly provided updates on future developments. Managers can help re-establish the link between employee jobs and organizational success by scrutinizing their company's goals and translating the company's vision into employee meanings. Mr Kropp, one of the organization's leading engagement drivers, stated, their work contributes to our company goals, and effective employees are less concerned about their job safety because of the importance of their work to the organization's success. (Kropp, n.d.)

\subsection{Reinforcement of organizational mismanagement concepts}

The most important factor is psychological well-being, and adverse experiences by employees can have a negative psychologic impact of up to $35 \%$. To make matters worse, bullying increases by 33 per cent in times of insecurity. Administrators should allow whistleblowers to reveal dishonest behaviours, revoke networks to disclose misdemeanours, and emphasize punitive noncompliance in addition to modelling correct behaviour.

\subsection{Acceptance of the efforts of workers}

Managers must increase their appreciation efforts as COVID-19 disrupts and undermines employee engagement. A good recognition motivates not only the recipient to repeat his or her actions, but it can also serve as a warning to others. Recognition can take many forms other than currency benefits, such as public interest, signs of appreciation, growth potential, and low-cost benefits. Management should take advantage of the opportunity to help all employees. This demonstrates the company's commitment to long-term employee success.

\subsection{Innovation Accelerate Interaction}

The disruption and transformation in this period continue to necessitate creativity and risk-taking for employee engagement and organizational performance, even though managers and workers are more risk-averse in a competitive environment. The removal of HIPOs who are more interested in this type of opportunity is severe because of creativity and risk management limitations. Managers should set goals and provide radical innovation or process change opportunities while considering new investment constraints. This is especially important when a team or organization faces difficulties due to a process disruption or a market impact.

Employee involvement refers to an employee's emotional commitment to his employer and colleagues, as well as his mission and goals. It is NOT about job satisfaction, high pay, or expressing gratitude to an employee after a long day's work. Unfortunately, many businesses mistake viewing employee involvement as a matter of human resources. If you own a business, this article is for you as well. 


\section{Impact of Covid-19 on Employee Productivity and Organizational Commitment in Afghanistan}

- The government has many options to explore to mitigate COVID-19 economic consequences. The country must depend on foreign partners and development agencies to assist the economy.

- Encouraging economic activity through country-wide development programmes requires a more significant development budget. Potential areas for investment may be potential infrastructure, health and education, particularly in rural areas.

- Government purchases at acceptable prices may reduce losses to deal with the uncertainty linked to exports of agricultural products, remarkably fresh fruit. However, the private sector, especially the hit industries, will require the tax relief to survive the losses and recover.

- The government could also have subsidized rates for services, including electricity. The financial strain on the government will undoubtedly increase in both steps. The government could allow certain industries, through strictly regulated steps, to start their production.

- There are two ways to regain public and business faith in order to fight the crisis, in addition to the policy choices.

- First, significant progress on the peace talks between the Afghan government and the Taliban.

- Second, the resolution of the dispute between President Ashraf Ghani and former CEO Abdullah Abdullah concerning the result of the 2019 presidential election. Funding is enabled when major donors are battling their financial problems and dealing with human victims due to the pandemic.

- On the other hand, a crisis will build both an atmosphere of stimulus and positive public sentiments for private sector investment.

- In Afghanistan and other affected countries, the pandemic is at its peak. Therefore, high priority should also definitely be added to humanitarian assistance, for which the media, government and private sectors have to collaborate. In the meantime, the administration must plan to deal with the future economic crisis.

The situation in Afghanistan is very different. Such incentives necessitate funding and strong institutions in Afghanistan, both of which are lacking. Almost half of the government spending was paid for, with the remainder funded through donations. Current revenue sources are expected to decline this year, reducing its ability to meet its budget. Unfortunately, during President Ashraf Ghani's first term, the main economic bodies, including the ministries of finance, economy, trade and industry, and the Da Afghanistan bank, were and continue to be dominated by acting ministers and governors (Central Bank). The country's largest financial entity, the Ministry of Finance, was divided into three autonomous bodies by presidential decree a month ago. This decision is currently being 
revised following the most recent reports, and rumours of its revocation have raised concerns about Afghanistan's financial institutions.

\section{Impact of Covid-19 on Employee Productivity and Organisational Commitment in India}

- Effective performance management provides a shared awareness of what people or teams must do while learning new skills to carry on business effectively.

- It is an all-year-long continuous mechanism of contact between employers and workers.

- Performance assessments help assess employee performance against targets and define various categories' expectations for positions, levels, and employment. In addition, performance control is a valuable way of distinguishing between low and high-performance workers.

- Remote working with almost $99 \%$ of workers at home has become normal. More important than ever is technology.

- Cost savings: In the following months, businesses will be handling cash flows through cost-saving measures:

- Responsible recruitment or freezing: companies recur to freezing, and vital and alternative recruitment will only occur once the economy is revived.

- Optimization of the workforce and pay-cuts: optimization to some degree can be necessary. The situation of Covid-19 will lead to a global workforce reduction as companies can save money through pay cuts.

- Travel \& Expenses: Businesses should dramatically reduce travel and marketing expenses.

- Productivity for employees: In the coming months the productivity of employees will be closely monitored and followed more than ever before due to distant work

- Staff involvement: Lockdowns have resulted in employees' anxiety, anger, and burnout. It is indispensable to improve employee morale and to communicate frequently with every employee. Employee participation is crucial, and the HR teams need to make every effort to make sure that employees connect with each other.

- JLL has also taken significant initiatives such as one-on-one connections to workers, virtual education and growth, fun activities and team creation, such as WhatsApp competitions, motivational storytelling, wellness sessions.

- Commitment activities: the Covid-19 worsened the unfortunate situation that resulted in employee disengagement. In addition, the organizations initiated online team building activities, such as online family engagement, online courts, webinars, counselling sessions, team meetings, virtual learning and development.

Technology: HR is revisiting its processes as the digital approach grows, ranging from talent acquisition, onboarding, interaction, learning and growth to outsourcing. With the help of platforms 
such as WebEx and WhatsApp, talent management teams at JLL have switched to virtual recruiting, ensuring applicant protection and sustained business support. They also provide continuous learning by creating online learning sessions and courses. The dependencies on HR staff for daily requests and policies have been minimized on the Heres Intranet websites. They provide continuous support to new hires through Webex, WhatsApp, Microsoft teams while working from home without face-to-face interactions via a remote onboarding programme.

\section{Recommendation for organizational commitment during this era}

\subsection{Counselling and coordination}

HR managers must maintain a two-way dialogue with their employees to ensure employee participation in communication efforts. For example, provide effective therapy for workers to alleviate their loneliness anxiety, release their fears, or relieve tension.

\subsection{Workers require assistance}

Employees do not want to be viewed as faceless cogs in a giant machine; they want to understand the unique value each brings to the organization. Employers have begun to accept this utility as well. Human resource practitioners must understand, embrace, and communicate this factor. In order to allow frequent conversations between line managers and employees, HR should provide management with appropriate guidance on the best response to sensitive issues of a post-COVID-19 pandemic, such as work safety, alternative modules of work, effect on personnel, and stress in the work environment.

\subsection{Reinforcing organizational principles}

The most significant influence on emotional safety is job well-being — an inexperienced employee can reduce psychological concerns re job safety by up to 35\%. To make matters worse, employee bullying increases by 33\% during times of insecurity. HR managers should enable, recall the networks of misconduct reporting, and highlight disciplinary action for post - Covid-19 nonconformity, in addition to modelled correct actions.

\subsection{Appreciate employee efforts}

Because COVID-19 causes significant disruption and undermines employee participation, HR managers must strengthen their appreciation programs and efforts. Effective recognition inspires the recipient and frequently serves as a clear indicator of behaviour to other employees. Appreciation can 
take many forms, including public recognition, gratitude tokens, opportunities for advancement, and low-cost benefits in exchange for monetary rewards. This increases the company's commitment to the employee's long-term success.

\subsection{Innovation Engagement}

Disruptive and risk-taking demands are becoming increasingly crucial for employee engagement and organizational performance in this unprecedented period of change and disruption. The disengaging effect of restrictions on the growth and risk-taking method is especially severe for high potential employees (HIPO) who are demotivated. Even if the company's new investment budget is limited, HR managers must emphasize the importance of process changes or incremental innovation and provide opportunities for them.

\subsection{Educating and equipping employees}

Employees must be educated and informed on COVID-19, safety tips, and wellness information. In this case, HR must communicate the company's actions. HR can create exciting articles on the activity feed about the growing events and topics in this area.

\subsection{Employee Well-being}

After acknowledging the distress and tension caused by the COVID-19 pandemic, HR must place a greater emphasis on the mental health and general well-being of its employees. Holistic benefits are popular for an organization's well-being. These advantages provide financial security and mental well-being. Although the packages for these services vary, the goal is to provide employees with benefits that go above and beyond traditional healthcare.

\subsection{Employee upscale}

Staff want to be treated as individuals, as evidenced by the trend toward personalization. Employees are shown support through the improvement, development, and learning systems. This allows employees to feel respected while also filling knowledge gaps in the business. According to a Deloitte survey, employees are the primary reason for their "inability to learn and grow."

Developing New Age Policies - In light of the business continuity plan for these needs following COVID-19, organizations must have processes, procedures, and policies in place. For example, if an office or plant is closed or affected, organizations must review their policies on flexibility, remote work, and contract staffing and review and explain their pay and benefits policies. 


\subsection{Looking forward}

While these measures have become the new job of an HR professional, they may not be suitable for every business. However, in the post-COVID-19 world, all HR should shift toward a more humanistic approach, where employees improve their working conditions.

HR professionals can work together to increase employee confidence and impressions by reacting or responding to crises and uncertainties. In addition, HR professionals can aid these initiatives.

\section{Conclusion}

Most organizations have begun to prepare scenarios and respond to the business continuity required to ensure post-COVID-19 business continuity. In order to re-establish competitiveness and provide staff experience, organizations must foster trust and openness.

Following COVID-19, organizations must revise their business strategies and operating procedures. They need dedicated employees now more than ever to get them through this challenging period. Workers can cope with feelings of fear, loneliness, and apprehension, among other things. In this scenario, the role that HR professionals play becomes critical. However, when social distancing is introduced and practised, it is not easy for HR practitioners to provide consistent processes, strategies, and commitments.

According to McKinney's research, leaders should change their policies and make their workforce believe that the instinct for organizational changes is correct and in their favour. First, the manager should focus on being action-oriented and empathetic to build trust and affiliation. Second, in addition to the employees' basic needs, there should be a trusting relationship and social cohesion, which affects the employees' emotional well-being and work effectiveness.

Given all of these challenges, human resources will be an organization's lifeline, and they must take care of and faithfully manage the post-COVID-19 situation. These issues, in particular, are primarily concerned with the human aspects of the global pandemic, and the HR position post-COVID-19 can be transformed.

As a result, some activities can be included in HR's new role, and the effects of the global pandemic can be investigated in various ways.

Furthermore, the findings indicated that management could improve its commitment to pay, policies, and working conditions in the organization during COVID-19. This can be addressed by enhancing online and offline worker experiences and intensifying direct debate on issues. In order to improve 
organizational involvement, organizational variables such as salary scales, workers' feedback on policy development, and the work environment should be improved.

\section{References}

Agarwal, P. (2021). Shattered but smiling: Human resource management and the well-being of hotel employees during COVID-19. International Journal of Hospitality Management, 93(June 2020), 102765. https://doi.org/10.1016/j.ijhm.2020.102765

Arora, S., \& Vyas, D. S. (2020). Job satisfaction at the time of COVID-19 : An investigation of information technology sector in India. Mukt Shabd Journal, 9(9), 251-263.

Chaudhary, V., Mohanty, S., Malik, P., Apsara Saleth Mary, A., Pai Maroor, J., \& Nomani, M. Z. M. (2021). Factors affecting virtual employee engagement in India during Covid-19. Materials Today: Proceedings, xxxx, 1-5. https://doi.org/10.1016/j.matpr.2021.05.685

Demirovi, D., Radovanovi, M., Tretiakova, T. N., \& Hadoud, A. (2021). International Journal of Hospitality Management Will we have the same employees in hospitality after all? The impact of COVID-19 on employees' work attitudes and turnover intentions. 94(October 2020).

Filimonau, V., Derqui, B., \& Matute, J. (2020). The COVID-19 pandemic and organizational commitment of senior hotel managers. International Journal of Hospitality Management, 91(July), 102659. https://doi.org/10.1016/j.ijhm.2020.102659

Hashemi, A. (2021). Effects of COVID-19 on the academic performance of Afghan students' and their level of satisfaction with online teaching. Cogent Arts and Humanities, 8(1). https://doi.org/10.1080/23311983.2021.1933684

Jaros, S. J., Jermier, J. M., Koehler, J. W., \& Sincich, T. (1993). Effects of Continuance, Affective, and Moral Commitment on the Withdrawal Process: An Evaluation of Eight Structural Equation Models. The Academy of Management Journal, 36(5), 951-995. https://doi.org/10.2307/256642

Kaushik, M. (2020). The Impact of Pandemic COVID -19 in Workplace. European Journal of Business and Management, June, 8-18. https://doi.org/10.7176/ejbm/12-15-02

Kropp, B. (n.d.). No Title. Gartner. https://www.gartner.com/en/newsroom/press-releases/2020-03-25gartner-identifies-six-initiatives-hr-can-undertake-t

Meyer, J. \& Allen, N. (1997). "Commitment in the Workplace: Theory, Research, and Application", Sage Publications.

Mohammad Qais Rezvani, Solkhe, D. A., Huseynov, D. R., Vijay, S. \& Hasanzade, A. (2020). 
EFFECT OF COVID 19 PANDEMIC ON WORKFORCE IN RURAL SECTOR: EVIDENCE FROM INDIA AND AFGHANISTAN. УКРАЇНСЬКААСОЦІАЦІЯ

ВИКЛАДАЧІВІДОСЛІДНИКІВ СВРОПЕЙСЬКӦ̈ІНТЕГРАЦЇ̈, Випуск V, 145-154.

Ogden, H. B., Fallowfield, J. L., Child, R. B., Davison, G., Fleming, S. C., Delves, S. K., Millyard, A., Westwood, C. S., \& Layden, J. D. (2020). Influence of aerobic fitness on gastrointestinal barrier integrity and microbial translocation following a fixed-intensity military exertional heat stress test. European Journal of Applied Physiology, 120(10), 2325-2337. https://doi.org/10.1007/s00421-020-04455-w

Radita, F. R., Augustin, W., Amri, A., Supiana, N., Sasono, I., \& Pramono, T. (2021). Work-Family Conflict among Employees: What is the Role of Religiosity on Job Satisfaction and Performance. February, 45-59. https://doi.org/10.51386/25815946/ijsms-v4i1p105

Vaziri, H., Casper, W.J., Wayne, J.H. \& Matthews, R.A. (2020). WORK-FAMILY PROFILE TRANSITION DURING COVID-19. Journal of Applied Psychology., 1-47. https://doi.org/10.1037/apl0000819

Venkatesh, V. (2020). Impacts of COVID-19: A research agenda to support people in their fight. International Journal of Information Management, 55(xxxx), 102197. https://doi.org/10.1016/j.ijinfomgt.2020.102197 